\title{
Transport and Surface Properties of Molten Cd-Zn Alloys
}

\author{
I. Koirala ${ }^{1,2}$, B. P. Singh ${ }^{1}$, I. S. Jha ${ }^{3}$ \\ ${ }^{1}$ University Department of Physics, T.M. Bhagalpur University, Bhagalpur, India \\ ${ }^{2}$ Central Department of Physics', Tribhuvan University, Kirtipur, Nepal \\ ${ }^{3}$ M.M.A.M. Campus, Biratnagar, Tribhuvan University, Nepal \\ ${ }^{2}$ E-mail: ishwar_koirala@yahoo.com
}

\begin{abstract}
Simple statistical theory has been used to report the thermo-physical properties of mixing in liquid Cd-Zn alloys. The energetic of mixing in liquid alloys has been analyzed through the study of surface properties (surface tension, surface concentration) and transport properties (diffusivity, viscosity). Negative deviation from Raoultian behaviour has been observed in the computed mixing parameters (viscosity, surface tension) of the alloys. The computed results support a weak phase-separation tendency in molten Cd-Zn system.
\end{abstract}

Key words: Thermo-physical properties, Raoultian behavior, diffusivity, surface segregation

\section{INTRODUCTION}

Alloys are industrial or commercial materials, which are grown from molten state. Liquid alloys are disordered materials which have short range order. Properties of disordered materials are much more difficult to understand than those of crystals and the complexity in the properties of mixing of binary liquid alloys is less understood. Therefore, the study of the properties of binary liquid alloys demands extensive theoretical investigations. Theoreticians have long been attempting to understand the properties of liquid alloys on the basis of the interactions between atoms or molecules (Flory, 1942; Gugenheim, 1952; Harrision, 1966; Lebowitz, 1964; Faber, 1972; Shimoji, 1977; Bhatia et al. 1973; Alonso \& March, 1982; Bernu et al. 1987; Li \& Tosi, 1989; Singh et al. 1990 \& 1993; Singh \& Sommer,1992; Novakovic, 2010).

Metal alloys are generally more beneficial over metals in various fields of technology such as engineering and metallurgical science for their increased mechanical strength, heat resistance, chemical resistance, decreased production costs, and wide range of colours. Cadmium is highly reactive metal in group IIB of periodic table. Compounds and alloys of this group have been widely used in fabricating solid state electronic components. Cadmium is used in many types of solder for standard electromotive force cells, Ni-Cd batteries, pigments, coatings, stabilizers and as barrier to control atomic fission. It is also used in electroplating of automotive, aircraft and in photoelectric cell in fire protection systems (Koirala et al. 2013). Cadmium-zinc is one of the numerous metal alloys, which has potential applications in bearing assemblies, ballasts, casting, step soldering, radiation soldering etc. Small content of cadmium lowers the melting point of cadmium-zinc alloys, improves thermal and electrical conductivities and increases mechanical properties such as hardness, wear resistance, tensile and fatigue strength (Adhikari et al. 2013).

The knowledge of transport properties such as diffusivities and viscosities of the metals in the liquid phase are required for many metallurgical processes and heterogeneous chemical reactions. On the other hand, knowledge of surface properties is essential for understanding of the surface related phenomenon such as corrosion, welding, casting, gas absorption, wetting characteristics of solders and kinetics of phase transformation (Prasad et al. 1991).

In the present work, we intend to explain the alloying behavior of Cadmium-Zinc liquid alloy on the basis of simple statistical model (Singh et al. 1990). It is a statistical mechanical model in which the grand partition function is used to obtained analytic expressions for the conditional probabilities enumerating the occupation of two neighbouring sites by the atoms of the constituent elements in terms of the ordering energy. The ordering energy, an important input parameter, is used for all calculation which is temperature dependent. We study the concentration dependent thermo-physical properties of mixing of liquid $\mathrm{Cd}-\mathrm{Zn}$ alloys at $800 \mathrm{~K}$. The energetic of mixing as well as the negative deviation from Raoultian behavior for transport and surface properties has been discussed. It is known that for segregating alloys the size effects have an appreciable influence on their surface properties (Singh \& Sommer, 1992). The degree of effects increases together with a preference of a system toward phase separation.

\section{MATERIALS AND METHODS Transport properties}

The transport properties such as viscosity, chemical diffusion coefficients etc may help to gain knowledge 
about the mixing behaviour of binary liquid alloys at the microscopic level. Viscosity $(\eta)$ of liquid alloys is equally important in the understanding of the atomic level structure and interactions. As in the case of thermodynamic functions, the composition dependence of $\eta$ of liquid alloys is also found to exhibit either a linear variation, or positive or negative deviations from the linear law. A simple formula for the investigation of viscosity of a binary solution is

$\eta=\eta_{\text {id }}\left[1-x(1-x)\left(\frac{2 \omega}{k_{B} T}\right)\right]$

But, $\quad \eta_{\mathrm{id}}=\mathrm{x} \eta_{\mathrm{A}}^{0}+(1-\mathrm{x}) \eta_{\mathrm{B}}^{0}$

where $\eta_{i}^{0}$ is the viscosity of pure component $i, \omega$ is the interchange energy or order energy and $x$, the concentration of the components (Moelevyn-Hughes, 1964).

The mixing behaviour of the alloy forming molten metals can also be studied at the microscopic level in terms of coefficient of diffusion. The mutual diffusion coefficient $\left(\mathrm{D}_{\mathrm{M}}\right)$ of binary liquid alloys can be expressed in terms of activity $\left(f_{i}\right)$ and self- diffusion coefficient $\left(D_{\text {id }}\right)$ of pure component with the help of Darken's equation (Darken \& Gurry, 1953).

$$
\frac{D_{M}}{D_{i d}}=\frac{d \ln f_{i}}{d x_{i}} \text {. }
$$

Considering only the energetics of the nearestneighbour bond, we obtain an expression for $\mathrm{D}_{M}$

$$
\begin{aligned}
& \frac{\mathrm{D}_{M}}{\mathrm{D}_{\mathrm{id}}}=\left[1-\mathrm{x}(1-\mathrm{x})\left(\frac{2 \omega}{\mathrm{k}_{\mathrm{B}} \mathrm{T}}\right)\right] \ldots \ldots \ldots \ldots \\
& \text { with } \quad \mathrm{D}_{\mathrm{M}}=\mathrm{xD}_{\mathrm{B}}+(1-\mathrm{x}) \mathrm{D}_{\mathrm{A}}
\end{aligned}
$$

where $D_{A}$ and $D_{B}$ are the self-diffusion coefficients of pure components $\mathrm{A}$ and $\mathrm{B}$ respectively.

The ratio $D_{M} / D_{\text {id }}$ indicates the mixing nature of molten alloys; $\mathrm{D}_{\mathrm{M}} / \mathrm{D}_{\mathrm{id}}<1$ indicates the tendency of homocoordination while $D_{M} / D_{\text {id }}>1$ indicates the tendency of hetero-coordination and $\mathrm{D}_{\mathrm{M}} / \mathrm{D}_{\mathrm{id}}$ approaches 1 for ideal mixing (Guggenheim, 1952; Darken \& Gurry, 1953; Singh \& Sommer, 1992).

\section{Surface properties}

For the processing of materials and productions in the metallurgical industry, knowledge of surface phenomena like surface segregation and surface tension is essential. It has been noted that many properties of physical relevant such as mechanical behaviour, kinetics of phase transformation, catalytic activity of alloy catalyst and thin film can not be explained without understanding surface phenomena. Surface segregation results from the interaction among the atoms and surface tension, is the enrichment of the surface by the atoms of the particular component element in a binary alloy (Prasad et al. 1991 \& 1998). In the statistical formulation of Prasad et al. (1991 \& 1998) binary liquid alloy is considered to have a layered structure near the surface with thermodynamic equilibrium existing between the species at the surface and in the bulk. The surface properties of liquid alloys are influenced by their bulk thermodynamic properties. The surface grand partition function is related to the surface tension $\tau$ by the expression (Prasad et al. $1991 \&$ 1998).

$$
\Xi^{\mathrm{S}}=\exp \left(\frac{-\mathrm{S} \tau}{\mathrm{k}_{\mathrm{B}} \mathrm{T}}\right)=\exp \left(\frac{-\mathrm{N}^{\mathrm{S}} \tau \xi}{\mathrm{k}_{\mathrm{B}} \mathrm{T}}\right)
$$

where $S$ is the surface area and $\xi$ is the mean area of the surface per atom and is defined as $\xi=\mathrm{S} / \mathrm{N}^{\mathrm{s}}$, and $\mathrm{N}^{\mathrm{s}}$ is the total number of atoms at the surface. $\mathrm{k}_{\mathrm{B}}$ is the Boltzmann constant.

A pair of equation for surface tension of the binary liquid alloys in terms of activity coefficient $\left(\gamma_{i}\right)$ of the alloy components and interchange energy parameter $(\omega)$, at the given temperature $\mathrm{T}$, proposed by Prasad et al, have been reduced in the simple form, using zeroth approximation as

$$
\begin{gathered}
\tau=\tau_{\mathrm{A}}+\frac{\mathrm{k}_{\mathrm{B}} \mathrm{T}}{\xi} \ln \frac{\mathrm{x}^{\mathrm{s}}}{\mathrm{x}}+\frac{\omega}{\xi}\left[\mathrm{p}\left(1-\mathrm{x}^{\mathrm{s}}\right)^{2}+(\mathrm{q}-1)(1-\mathrm{x})^{2}\right] \ldots . .7(\mathrm{a}) \\
\tau=\tau_{\mathrm{B}}+\frac{\mathrm{k}_{\mathrm{B}} \mathrm{T}}{\xi} \ln \frac{\left(1-\mathrm{x}^{\mathrm{s}}\right)}{(1-\mathrm{x})}+\frac{\omega}{\xi}\left[\mathrm{p}\left(\mathrm{x}^{\mathrm{s}}\right)^{2}+(\mathrm{q}-1)(\mathrm{x})^{2}\right] \ldots . .7(\mathrm{~b})
\end{gathered}
$$

where $\tau_{\mathrm{A}}$ and $\tau_{\mathrm{B}}$ are the surface tension values for the pure components $\mathrm{A}$ and $\mathrm{B}$ respectively; $\mathrm{x}$ and $\mathrm{x}$ are the bulk and surface concentrations of the alloy component; $\mathrm{p}$ and $\mathrm{q}$ are the surface coordination fractions, which are defined as the fraction of the total number of nearest neighbors made by atom within its own layer and that in the adjoining layer. For $\mathrm{p}$ and $\mathrm{q}$, the following relation is available (Prasad et al. 1991 \&1998; Novakovic et al. 2005; Novakovic, 2010).

\section{$\mathrm{P}+2 \mathrm{q}=1$}

For closed packed structure, $p=0.5$ while $q=0.25$ (in view of the disordered structure and relaxation effect of the surface layer $\mathrm{p}$ and $\mathrm{q}$ should be treated as parameters (Prasad et al. 1991)).

The pair of equations 20(a) and 20(b) can be solved numerically to obtain $x^{\mathrm{s}}$ as a function of $\mathrm{x}$. Obviously the surface concentration depends upon the surface tension of the $i^{\text {th }}$ component in the pure state $\left(\tau_{i}\right)$, surface area per $\operatorname{atom}(\xi)$, order energy $(\omega)$ and the coordination 
fractions ( $\mathrm{p}$ and $\mathrm{q}$ ). This approach is useful because it can be used to investigate the dependence of surface composition on order energy and surface coordination.

The mean atomic surface area $\xi\left(=\mathrm{A} / \mathrm{N}^{\mathrm{s}}\right)$ is given as

$$
\xi=\sum c_{i} \xi_{i} \quad(i=A, B)
$$

Where the atomic area of hypothetical surface for each component is given as (Prasad et al. 1988) :

$$
\xi_{\mathrm{i}}=1.102\left(\Omega_{\mathrm{i}} / \mathrm{N}_{0}\right)^{2 / 3}
$$

where $\Omega_{\mathrm{i}}$ is the molar volume of the species $\mathrm{i}$ and $\mathrm{N}_{0}$ stands for Avogadro number.

On the basis of assumption of monatomic surface layer, Butler's approach (Butler, 1932) of surface tension $\tau$ of liquid solution can be expressed as

$$
\tau=\frac{\mu_{\mathrm{A}}^{\mathrm{s}}-\mu_{\mathrm{A}}^{\mathrm{b}}}{\alpha_{\mathrm{A}}}=\frac{\mu_{\mathrm{B}}^{\mathrm{s}}-\mu_{\mathrm{B}}^{\mathrm{b}}}{\alpha_{\mathrm{B}}}=\ldots \ldots . .=\frac{\mu_{\mathrm{i}}^{\mathrm{s}}-\mu_{\mathrm{i}}^{\mathrm{b}}}{\alpha_{\mathrm{i}}}
$$

Where $\mu_{i}^{\mathrm{s}}, \mu_{\mathrm{i}}^{\mathrm{b}}$ and $\alpha_{\mathrm{i}}$ represent respectively the chemical potential in the hypothetical surface and that in the bulk and molar surface area of pure component i (A or B).

Equation (10) yields the expressions for surface tension in terms of partial excess free energy of mixing in $\operatorname{bulk}\left(G_{i}^{E, b}\right)$ and at the $\operatorname{surface}\left(G_{i}^{E, s}\right)$ and concentration in the bulk(x) and at the $\operatorname{surface}\left(\mathrm{x}^{\mathrm{s}}\right)$ as

$$
\begin{gathered}
\tau=\tau_{A}+\frac{1}{\alpha_{A}}\left(G_{A}^{E, S}-G_{A}^{E, b}\right)+\frac{R T}{\alpha_{A}} \operatorname{Inx}-\frac{R T}{\alpha_{A}} \operatorname{In} x \ldots .11(a) \\
\tau=\tau_{B}+\frac{1}{\alpha_{B}}\left(G_{B}^{E, S}-G_{B}^{E, b}\right)+\frac{R T}{\alpha_{B}} \operatorname{In}\left(1-x^{S}\right)-\frac{R T}{\alpha_{B}} \operatorname{In}(1-x) \quad \ldots 11(b)
\end{gathered}
$$

where $\tau_{\mathrm{A}}$ and $\tau_{\mathrm{B}}$ are surface tension of pure component $\mathrm{A}$ and $\mathrm{B}$ respectively.

The area of monatomic surface layer for the component $\mathrm{i}$ can be calculated by the relation (Butler, 1932).

$$
\alpha_{\mathrm{i}}=1.091 \mathrm{~N}_{0}^{1 / 3} \Omega_{\mathrm{i}}^{2 / 3}
$$

Where $\mathrm{N}_{0}$ is Avogadro's number and $\Omega_{\mathrm{i}}$ stands for molar volume of the component $\mathrm{i}$, can be calculated from its molar mass and density.

\section{RESULTS AND DISCUSSION}

The ordering energy, $\omega$, the temperature dependent quantity has been used as input energy parameter for the calculation of diffusivity, viscosity and surface tension for $\mathrm{Cd}-\mathrm{Zn}$ liquid alloys at $800 \mathrm{~K}$. It can be estimated from experimental value of excess free energy of mixing $\left(G_{M}^{X S}\right)$ through standard thermodynamic expression for equiatomic composition (Singh et al. 1990; Koirala et al. 2013). For this, we have

$$
\frac{\mathrm{G}_{\mathrm{M}}^{\mathrm{XS}}}{\mathrm{Nk}_{\mathrm{B}} \mathrm{T}}=\ln 2^{\mathrm{z} / 2}\left[1+\exp \left(-\omega / \mathrm{zk}_{\mathrm{B}} \mathrm{T}\right)\right]^{-\mathrm{z} / 2}
$$

From equation (13), the best fit value for $\omega$ is found to be

$\frac{\omega}{\mathrm{k}_{\mathrm{B}} \mathrm{T}}=+1.24$

The positive value of energy parameter $\left(\frac{\omega}{\mathrm{k}_{\mathrm{B}} \mathrm{T}}\right)$ suggests that there is higher tendency for like atoms to pair in the alloy which implies a homo-coordination system. However, the tendency of pairing is weak since energy parameter is small.

The ratio of the mutual and intrinsic-diffusion coefficients $\left(\frac{D_{M}}{D_{\text {id }}}\right)$ as a function of concentrations, has been calculated using the equation (4). The plot of $\frac{D_{M}}{D_{\text {id }}}$ verses concentration of cadmium in $\mathrm{Cd}-\mathrm{Zn}$ system is shown in Fig.1. The obtained diffusivity for the alloys system shows the values of $\frac{D_{M}}{D_{i d}}<1$ over the entire range of concentration which is indicative for the phase separation in the mixture. A minimum value of $\frac{D_{M}}{D_{i d}}=$ 0.38 for $\mathrm{x}_{\mathrm{Cd}}=0.5$, confirms a weak tendency for segregation.

The viscosity of the $\mathrm{Cd}-\mathrm{Zn}$ liquid alloy has been computed numerically from equation (1). The plot of $\eta$ verses bulk concentration of $\mathrm{x}_{\mathrm{Cd}}$ in $\mathrm{Cd}-\mathrm{Zn}$ liquid alloy is shown in Fig.2. In Fig. 2 small negative deviations from the linear law (Raoult's law) in viscosity isotherms $\eta(c)$ have been observed for the regular alloy which is the indicative of segregating system.

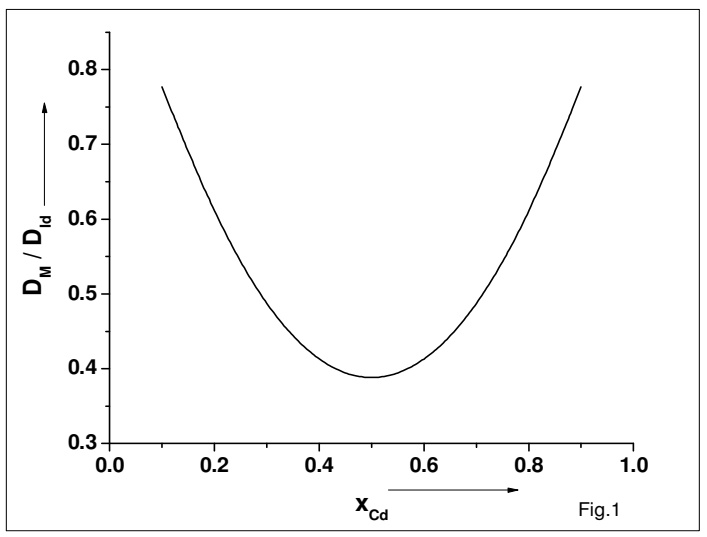

Fig. 1. Ratio of mutual and intrinsic diffusion coefficients $\left(D_{M} / D_{i d}\right)$ Vs concentration of cadmium $\left(x_{C d}\right)$ in liquid $\mathrm{Cd}-\mathrm{Zn}$ alloy at $800 \mathrm{~K}$. 


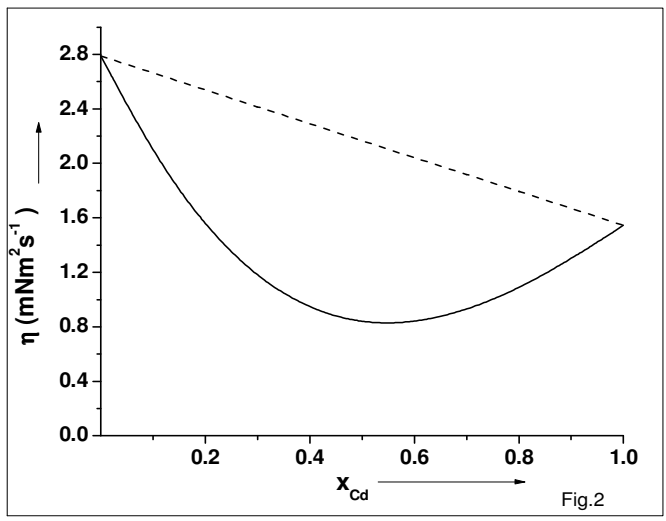

Fig. 2. Viscosity ( $\eta$ ) Vs concentration of cadmium $\left(\mathbf{x}_{\mathrm{Cd}}\right)$ in liquid $\mathrm{Cd}-\mathrm{Zn}$ alloy at $800 \mathrm{~K}$.

The surface concentrations and surface tension of $\mathrm{Cd}-\mathrm{Zn}$ have been computed numerically from the equations 7(a) and 7(b), where interchange energy, $\omega$ is used instead of $\gamma_{\mathrm{A}}$ and $\gamma_{\mathrm{B}}$ as used in Prasad's model. For this, we need experimental data of density and surface tension of the components at the working temperature. We have calculated the density and surface tension for the components Cd and Zn (Iida \& Guthrie, 1988; Brandes \& Smithells, 1983) at the working temperature $\mathrm{T}=800 \mathrm{~K}$ by using the following equations

$$
\begin{aligned}
& \rho_{\mathrm{Cd}}(\mathrm{T})=8.709-1.16 \times 10^{-3} \mathrm{~T} \\
& \rho_{\mathrm{Zn}}(\mathrm{T})=7.336-1.1 \times 10^{-3} \mathrm{~T} \\
& \tau_{\mathrm{Cd}}(\mathrm{T})=0.5854-0.26 \times 10^{-4} \mathrm{~T} \\
& \tau_{\mathrm{Zn}}(\mathrm{T})=0.8996-1.7 \times 10^{-4} \mathrm{~T}
\end{aligned}
$$

The mean atomic surface area $\xi$ has been calculated by using equations (8) and (9). For calculating surface tension we used same estimated energy parameter, $\omega$. At first, surface concentrations of cadmium in alloy $\mathrm{Cd}-\mathrm{Zn}$ have been obtained as a function of bulk concentration by concurrently solving the equations 7(a) and 7(b). Using the obtained values of surface concentrations we computed the surface tension of $\mathrm{Cd}-\mathrm{Zn}$ liquid alloys at temperature $800 \mathrm{~K}$ for whole concentration range.

For the computation of surface concentration and surface tension of the Cd-Zn alloy on using Butler's approach, the partial excess free energies of mixing of pure components of the alloys have been taken from the ref.(Hultgren et al. 1973). By concurrently solving the equations 11(a) and 11(b), surface concentrations of $\mathrm{Cd}$ in alloy Cd-Zn have been obtained as a function of bulk concentration and then using the obtained values of surface concentrations we computed the surface tension of Cd-Zn liquid alloys at temperature $800 \mathrm{~K}$ for whole concentration range.

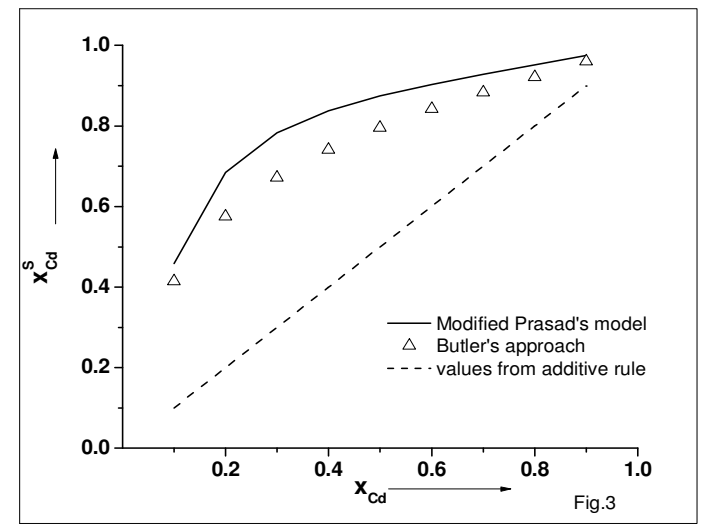

Fig. 3. Surface concentration of cadmium $\left(x_{C d}^{S}\right) V s$ bulk concentration of cadmium $\left(\mathrm{x}_{\mathrm{Cd}}\right)$ in liquid $\mathrm{Cd}-\mathrm{Zn}$ alloy at $800 \mathrm{~K}$.

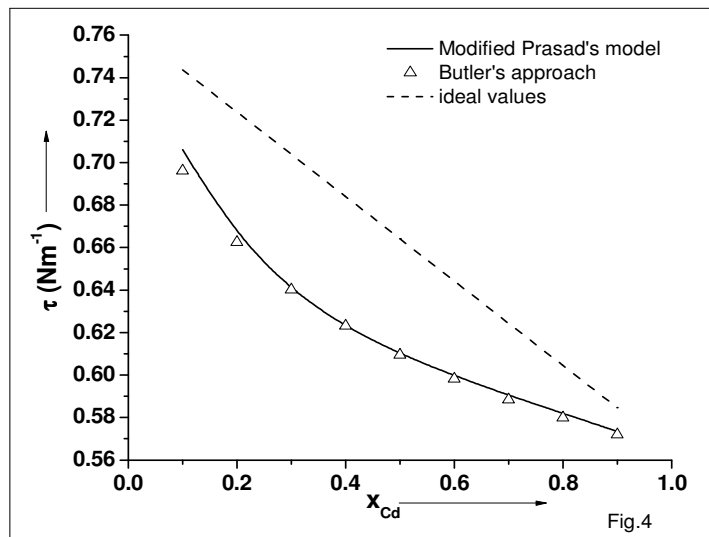

Fig. 4. Surface tension $(\tau)$ Vs bulk concentration of cadmium $\left(x_{C d}\right)$ in liquid $C d-Z n$ alloy at $800 \mathrm{~K}$.

Figs. (3) and (4) are respectively the plots of surface concentration and surface tension against bulk concentration of cadmium in liquid $\mathrm{Cd}-\mathrm{Zn}$ alloys at $800 \mathrm{~K}$. It is noticed that surface concentration of cadmium in $\mathrm{Cd}-\mathrm{Zn}$ alloys is found to be larger than concentration from additive rule; it increases with increase of its bulk concentrations (Fig. 3). Theoretical analysis gives that the computed surface tension for $\mathrm{Cd}$ $\mathrm{Zn}$ alloys at $800 \mathrm{~K}$ is less than ideal values at all concentration of cadmium; i.e. there is negative departure of surface tension from ideality. Two approaches predict that surface tension of $\mathrm{Cd}-\mathrm{Zn}$ liquid alloy decreases with increase of bulk concentration of zinc (Fig. 4). This is an indication that in the alloys there are more atoms of component with bigger atom at the surface. Hence, at the surface of $\mathrm{Cd}-\mathrm{Zn}$, bigger $\mathrm{Cd}$-atoms segregate at the surface in preference to $\mathrm{Zn}$-atoms throughout the entire composition. The segregation of the components may result from the differences surface tension, atom radius and electron configuration between solvent and solute. 


\section{CONCLUSIONS}

Following conclusions are drawn about liquid $\mathrm{Cd}-\mathrm{Zn}$ alloys at $800 \mathrm{~K}$ :

- The alloy is of a weakly interacting nature.

- It is of phase-segregating system.

- Viscosity isotherm of the alloy is found to deviate negatively from ideality.

- Consistency is occurred in the values of surface tension obtained from two approaches, negative departure of surface tension from ideality is observed.

- The surface of liquid Cd-Zn alloys is enormously rich with bigger $\mathrm{Cd}$ atoms.

\section{ACKNOWLEDGEMENT}

One of the authors (I. Koirala) would like to acknowledge to Prof. Dr. Lok Narayan Jha, Prof. Dr. Pradeep Raj Pradhan and Prof. Dr. Devendra Adhikari for fruitful suggestions and inspiring discussions.

\section{REFERENCES}

Adhikari, D., Singh, B.P. and Koirala R.P. 2013. Thermodynamic, Structural and Transport properties of molten Copper-Thallium Alloy. World Acad. of Sci, Eng. and Technology 77.

Alonso, J. A. and March, N. H. 1982. Concentration fluctuations in metallic liquid alloys.PhysicaB 114: 67.

Bernu, B., Hansen, J. P., Hiwatari, Y. and Pastore, G. 1987. Soft sphere model for the glass transition in binary alloys,pair structure and self diffusion. Phys. Rev. A 36: 4891.

Bhatia, A. B., Hargrove, W. H. and March, N. H. 1973. Concentration fluctuations in conformal solution and partial structure factor in alloys. J. Phys.C: solid state physics. 6: 621 .

Brandes, E. A. and Smithells, C. J. 1983. Metals Reference Book. Sixth Edition. Sec.14-6.

Butler J.A.V.1932. Thermodynamic of surface solution.Proc.R.Soc.A.135;348.

Darken, L.S. and Gurry R.W. 1953. Physical Chemistry of Metals. McGraw Hill, New York; 535.

Faber, T. E. 1972. Introduction to the theory of liquid metals. Cambridge Univ. Press, Cambridge.

Flory, J. 1942. Thermodynamics of high polymer solutions. J. Chem. Phys. 10: 51.

Guggenheim, E.A. 1952. Mixture. Oxford University Press, London.

Harrision, W.A. 1966. Pseudopotential in the Theory of metal, W.A.Benjamin,Inc.,New York.
Hultgren, R., Desai, P. D., Hawkins, D.T., Gleiser, M. and Kelley, K. K. 1973. Selected Values of the Thermodynamic Properties of Binary Alloys. ASM Metals Park, Ohio. 1013.

Iida, T. and Guthrie, R. I. L. 1988. The physical properties of liquid metals. Clarendon Press; Oxford. J. Non-Cryst. Solids 61-62: 279.

Koirala, I., Jha, I.S., Singh, B.P. and Adhikari, D. 2013. Thermodynamic, transport and surface properties in In-Pb liquid alloys. Physica B. 423:49.

Lebowitz, J. L. 1964. Exact solution of generalised Percus-Yevick equation for mixture of hard spheres. Phys. Rev.A 133: 895.

Li, W. and Tosi, M. P. 1989. Electron theory of longwavelength concentration fluctuations in liquid metal alloys. Il Nuovo Cim. 11(10): 1509.

Moelevyn-Hughes EA. 1964. Physical chemistry. Oxford, Pergamon.

Novakovic, R. 2010. Thermodynamics, surface properties and microscopic functions of liquid Al$\mathrm{Nb}$ and $\mathrm{Nb}$-Ti alloys. J.Non-Cryst.Solids. 356:1593.

Novakovic, R., Giuranno, D., Ricci, E. and Passerone, A. 2005. Surface and transport properties of $\mathrm{Ag}-\mathrm{Cu}$ liquid alloys. Surface Sci. 576: 175.

Prasad, L.C. and Singh, R. N. 1991. Surface segregation and concentration fluctuations at the liquid vapor interface of molten $\mathrm{Cu}-\mathrm{Ni}$ alloys. Phys.Rev.B. 44: 13768.

Prasad, L.C., Singh, R.N., Singh, V.N. and Singh, G.P. 1998. Correlation between bulk and surface properties of Ag-Sn liquid alloys. J. Phys.Chem. B.102:921.

Shimoji, M. 1977. Liquid metals. London Acad., London.

Singh, R.N. and Sommer F. 1992. Temperature dependence of the thermodynamic functions of strongly interacting liquid alloys. J.Phys. Condens. Matter. 4:5345.

Singh, R.N., Jha, I. S. and Sinha, S.K. 1993.The segregation-order transformation in $\mathrm{Cd}-\mathrm{Na}$ liquid alloy. J. Phys. Condens.Matter. 3: 2787.

Singh, R.N.,Mishra, I.K. and Singh, V.N. 1990. Local order in Cd-based liquid alloys. Phys.Condens. Matter. 2: 8457. 